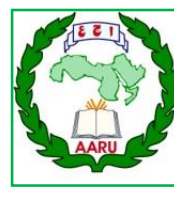

Arab Univ. J. Agric. Sci., Ain Shams Univ., Cairo, Egypt

29(2), 519-533, 2021

Website: http://ajs.journals.ekb.eg

DOI: 10.21608/ajs.2021.81485.1394

\title{
Effect of Electrolysis Technology on Saline Water under Utilize Nano-coated Electrodes
}

\author{
Hassan M Ali*, Yasser E Arafa, Khaled F El-Bagoury \\ Agricultural Engineering Dept, Fac of Agric, Ain Shams Univ, P.O. Box 68, \\ Hadayek Shoubra 11241, Cairo, Egypt \\ * Corresponding author: mohamedhassan@agr.asu.edu.eg
}

Received 20 June, 2021

Accepted 31 August, 2021

\begin{abstract}
In this work, electromagnetic field technology and electrolysis technology with aluminum electrodes coated with titanate nano-coating were combined in different investigated parameters: power types (Electrolysis pass (EP) and Electromagnetic pass (EMP)), voltage $(12 \mathrm{v}, 24 \mathrm{v}$ and $36 \mathrm{v})$ and nano-coating parameters (coated and uncoated). The designed water treatment unit was evaluated by recording the EC-meter readings for 60min (each $5 \mathrm{~min}$ ) at a flow rate of $51 / \mathrm{min}$. Results show that the best salt rejection rate was $3.4 \%$ when EMP was used before EP where four electrodes were coated. In contrast, the other parameters (EP, EMP+EP and EMP+EP (2 coated electrodes and 2 uncoated)) recorded the salt rejection rates $1.13 \%, 1.57 \%$ and $2.4 \%$, respectively. This study is promising and opens the way for integrating both electrolysis and electromagnetic field technologies with on-farm irrigation systems and enhancing their efficiency using nanotechnology.
\end{abstract}

Keywords: Electrolysis, Electromagnetic, Desalination technologies, Nano-coating, Titanate and Treated Water

\section{Introduction}

Agricultural activities consume more than two-thirds of the available water because the water is very necessary for the growth of plants (Fernando et al 2015). By the year 2050, food production must increase by $60 \%$ to ensure global food security. Accordingly, the demand for irrigation water will increase greatly to help meet this water demand (Malakar and Ray 2019).

Annually in Egypt, 17 billion cubic meters of agricultural wastewater is produced in Egypt (Assar et al 2019). On the other hand, groundwater salinity in Egypt ranges between 200 to 12,000 PPM (Abdel-Shafy and Kamel 2016). Groundwater with salt concentrations higher than $1500 \mathrm{ppm}$ used to irrigate crops should be done under good irrigation management. A salinity concentration above 6000 ppm is difficult for most crops to grow (Johnson and Zhang 2017).

Since 1970, electrolysis has been used in water desalination as it relies on an electrochemical process to reduce salts in water. Electrolysis depends on two electrodes, one is positive (anode), and the other is negative (cathode). When the current is connected to them, the positive ions move towards the cathode and the negative ions towards the anode (Sharbat 2016).

On the other hand, electromagnetic field has been reduced Sodium and Chloride ions in soil irrigated with electromagnetically treated water than untreated water, and it reduced the absorption of sodium ions by plant roots (Hachicha et al 2018). 
In recent years, there has been great interest in Titanate nanomaterials because they have exhibited several chemical and physical properties, the most important of which are their large surface area and their ability to ion exchange (Liu et al 2015). These properties could remove Sodium ions from saline water as a desalination process.

This study aimed to determine the effect of changing the flow rate and electrolytic voltage on reducing salts in the treated water and studied the effect of using titanate nano-coated aluminum electrodes on saline water under electromagnetic field effect.

\section{Materials and Methods}

Laboratory experiments were conducted in The On-Farm Irrigation Lab. at Agricultural Engineering Department, Faculty of Agriculture, Ain-shams University, Egypt, which located at $31^{\circ} 41^{\prime} 42.3^{\prime \prime} \mathrm{E}$ in longitude and $30^{\circ} 6^{\prime} 44.37 " \mathrm{~N}$ in latitude. However, all experiments had been conducted during the year of 2020, from Jan up to Nov.

\subsection{General Description of Investigated Water Treatment Unit}

The investigated Prototype of marginalquality water treatment unit is shown in (Fig 1). The unit consists of two different parts. The first part (Electromagnetic Pass), shown in (Fig 1 No. 6), consists of a coil rotated around a galvanized iron pipe and connected with a power supply with variable voltage power supply output to generate an electromagnetic field. The second part (Electrolysis Pass), shown in (Fig 1 No. 7), consists of four plates fixed into PVC pipe and connected with a variable voltage power supply output to generate an electric field at the water. Other components of the unit (Fig 1 No. 1, 2, 3, 4, 5) consists of a tank with dimensions width $0.7 \mathrm{~m}$, length $0.3 \mathrm{~m}$ and height $1.2 \mathrm{~m}$ filled with the water which used in this study, water was pumped out using a centrifugal pump $0.5 \mathrm{~kW}$ and it flows into an Electromagnetic pass (EMP) then into an Electrolysis pass (EP), Ultrasonic flow meter sensor was fixed on PVC pipe (diameter $32 \mathrm{~mm}$ ). After that, (EMP) and (EP) Installed between two valves which controlled the flow rate. Direct current (DC) was generated by variable voltage power supply connected to (EP) and (EMP) according to the experimental parameters.

\subsubsection{Electromagnetic Pass (EMP)}

A copper coil (Fig 2 No. 2) consists of a copper wire with a diameter of $10 \mathrm{~mm}$ and $6.5 \mathrm{~m}$ length was rotated as a coil around a pipe. The galvanized iron pipe (Fig 2 No. 1) internal diameter was $25 \mathrm{~mm}$ and coil covered $0.5 \mathrm{~m}$ from pipe length. The pass was designed to generate electromagnetic field for study its effect on marginal-quality Water.

\subsubsection{Electrolysis Pass (EP)}

Four plates from Aluminum (Fig 3 No. 2 , 3) with dimensions $(2 \times 35 \mathrm{~cm})$ and thickness $(2 \mathrm{~mm})$ were fixed with space between them $(10 \mathrm{~mm})$ and installed inside a PVC pipe (Fig 3 No. 1) with diameter $(50 \mathrm{~mm})$. Plastic insulator (Fig 3 No. 6) had fixed between plates to isolate them from each other, First and Third plates were connected with the positive electrode (Fig 3 No. 4), Second and Fourth plates were connected with the negative electrode (Fig 3 No. 5). The pass was designed to generate electric field for study its effect on marginal-quality Water. Electrolysis pass (EP was electrolyzed by two sides for each electrode, and electrodes effective surface area equal 560 $\mathrm{cm}^{2}$. 
Effect of Electrolysis Technology on Saline Water Under Utilize Nano-coated Electrodes

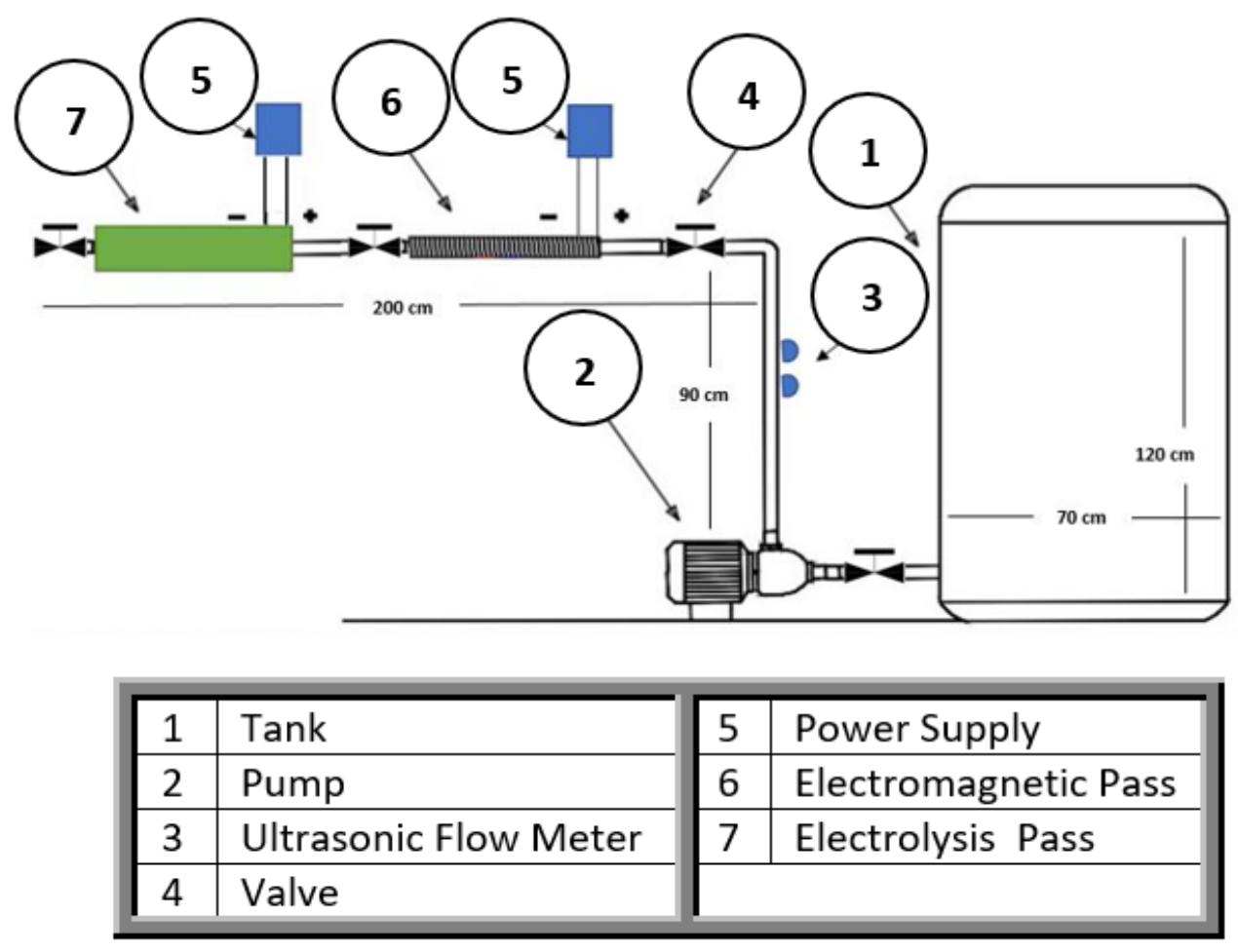

Fig 1. Experiment system installation.

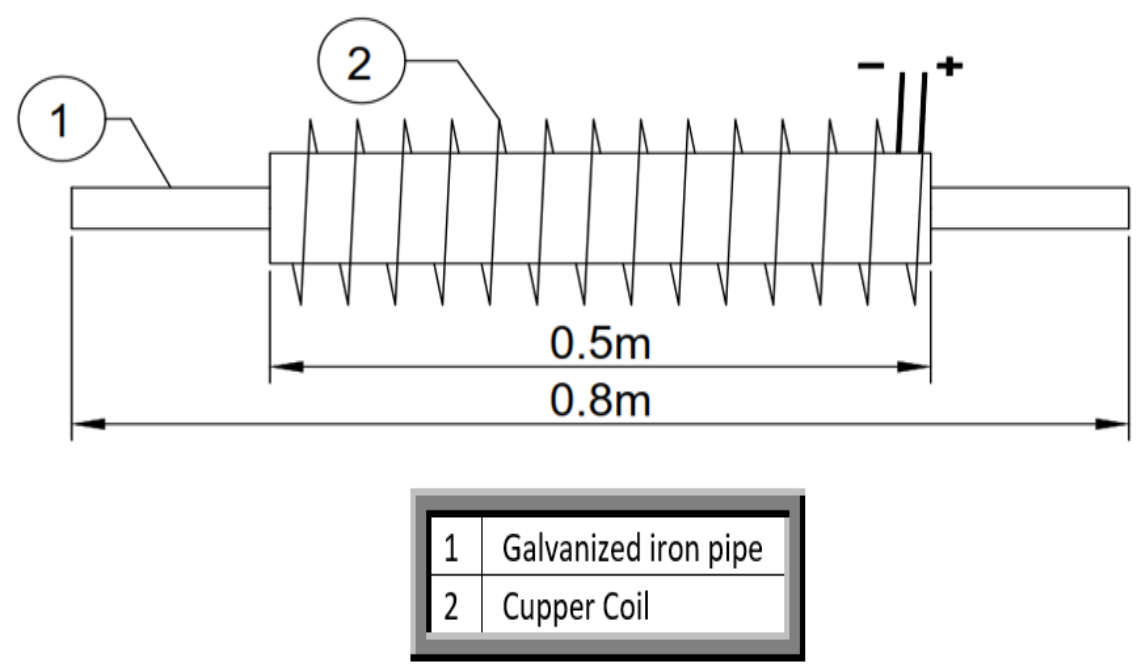

Fig 2. Electromagnetic Pass (EMP) installation. 


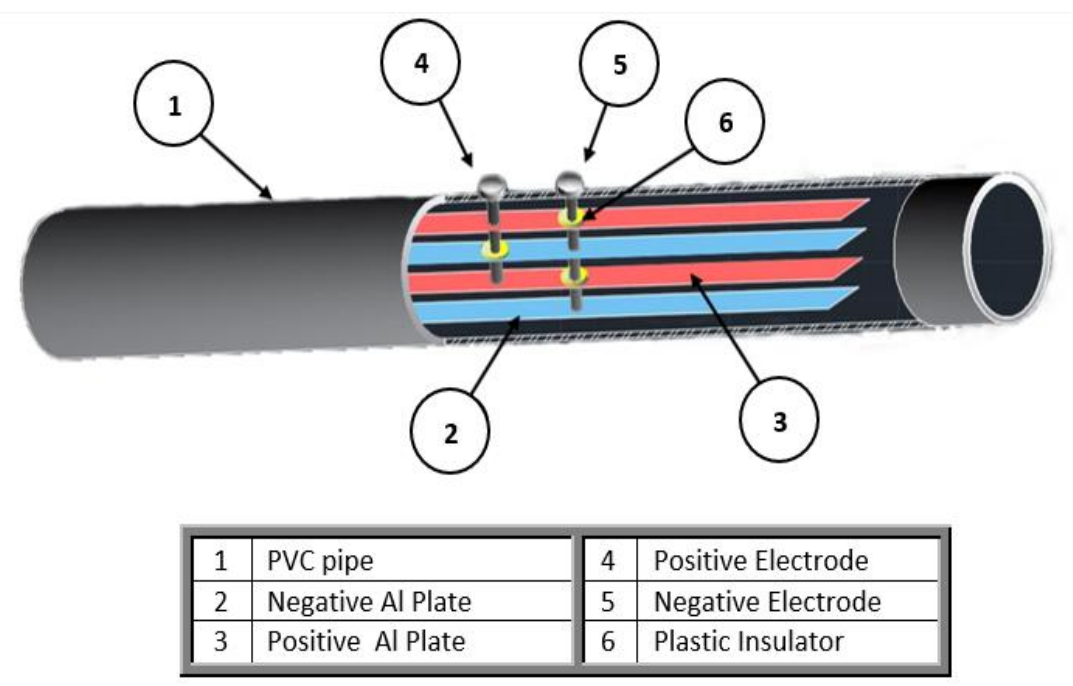

Fig 3. Electrolysis Pass (EP) installation.

2.2 Simulated Marginal-quality Water (SMW) and Preparation of Nano-coating 2.2.1 Simulated Marginal-quality Water (SMW)

One gram and half of the sodium chloride was determined from Equation (1) cited from Brouwer and Heibloem (1986). Total $\mathrm{NaCl}$ weight was added to distilled water. The solution was stirred until complete dissolution and the concentration of salts was measured in it by EC-meter. The salinity was estimated at 1500 ppm.

Total $\mathrm{NaCl}$ Weight $(\mathrm{g})=$ Volume of The Tank (L) ${ }^{*}$ Solution concentration $(\mathrm{g} / \mathrm{L})$

\subsubsection{Nano-coating Preparation}

Pure $\mathrm{TiO}_{2}$ was added into $500 \mathrm{ml}$ of 10 molar $\mathrm{NaOH}$ solution under stirring for $30 \mathrm{~min}$. After that, the mixed solution was added into a Teflon-lined stainless-steel autoclave and heated to $160^{\circ} \mathrm{C}$ for $23 \mathrm{hr}$. Thereafter, it was air-cooled to room temperature. The solution was washed many times with distilled water (Zaki and EL-Dek 2019). Finally, the solution was filtered with a filter paper and the filtrate was put into 0.1 molar hydrochloric solution and then it dried at $80^{\circ} \mathrm{C}$ for $4 \mathrm{hr}$ after washed many times with distilled water (Lai et al 2016). The $\mathrm{H}_{2} \mathrm{Ti}_{3} \mathrm{O}_{7}$ Nanomaterial Synthesis reactions were represented by the following Equations (2 and 3) according to (Lai et al 2016):

$$
\begin{aligned}
& 3 \mathrm{TiO}_{2}+2 \mathrm{NaOH} \longrightarrow \mathrm{Na}_{2} \mathrm{Ti}_{3} \mathrm{O} 7+\mathrm{H}_{2} \mathrm{O} \ldots . .(2) \\
& \mathrm{Na}_{2} \mathrm{Ti}_{3} \mathrm{O}_{7}+2 \mathrm{HCl} \longrightarrow \mathrm{H}_{2} \mathrm{Ti}_{3} \mathrm{O}_{7}+2 \mathrm{NaCl} \ldots \text { (3) }
\end{aligned}
$$

Nano-coating prepared by adding $7 \mathrm{~g}$ from $\mathrm{H}_{2} \mathrm{Ti}_{3} \mathrm{O}_{7}$ nanomaterial mixed with 63g of Polyvinylpyrrolidone (PVP) and put into distilled water $(25 \mathrm{ml})$. The solution was stirred for $10 \mathrm{~min}$, then coated into 6 Aluminum plates. Each plate was coated from both sides and left to dry at room temperature for $72 \mathrm{hr}$.

\subsection{Water Flow Characterizations}

The flow behavior was determined in some of the components of the water treatment unit, including the PVC pipe, the electromagnetic pass (EMP), and the electrolysis pass (EP). PVC pipe was indicated as control parameter and compared with EMP and EP. 
PVC pipe internal diameter (d) was $28.4 \mathrm{~mm}$ with length $0.75 \mathrm{~m}$. Flow rate was $51 / \mathrm{min}$ according to experimental parameters, and the flow velocity was measured by Ultrasonic Flow Meter, and it was $0.13 \mathrm{~m} / \mathrm{s}$. The flow in this pipe was turbulent as the Reynold's numbers was approximately 4000 .

Electromagnetic Pass (EMP) internal galvanized iron pipe diameter used in the pass was $25 \mathrm{~mm}$, and the flow rate was $51 / \mathrm{min}$ according to experimental parameters, and the flow velocity was measured by Ultrasonic Flow Meter, and it was $0.17 \mathrm{~m} / \mathrm{s}$. The flow in this pass was turbulent as Reynold's number was approximately 4700 . The length of the exposure to the electromagnetic field was $0.5 \mathrm{~cm}$ into EMP. So, water exposure time at EMP was approximately 2.94 seconds.

Electrolysis Pass (EP) water flow paths between electrodes and PVC pipe showed in Fig 4, and it demonstrated two sections into ED to study flow directions and flow state between narrow electrodes paths $(\mathrm{d}=10 \mathrm{~mm})$. Flow rate parameters in this study into EP was $5 \mathrm{l} / \mathrm{min}$, and flow velocity was $0.13 \mathrm{~m} / \mathrm{s}$ which measured by Ultrasonic Flow Meter. The Reynold's number in this case was approximately 1450 at flow rate $51 / \mathrm{min}$. According to Reynold's number values, flow state when water transferred from PVC pipe and EMP to EP at $5 \mathrm{~L} / \mathrm{min}$ apparatus became laminar rather than turbulent. While the length of the exposure to the electric field was $0.35 \mathrm{~m}$ into EP. So, water exposure time at EP was approximately 2.7 seconds at flow rate $51 / \mathrm{min}$.

(Table 1) illustrates flow state at three different system components (PVC - EMD ED) according to Reynold's number which measured by Ultrasonic flow meter and demonstrated characterizations of flow types within system such as flow velocity, and exposure time. From (Table 1), water treatment unit was evaluated under two flow states (Laminar and Turbulent).

\subsection{Studied Parameters}

\subsubsection{Voltage During Water Electrolysis}

The voltage was studied at (12-24-36) v by using variable voltage power supply output, the required voltage output connected with ED. The flow was controlled by closing the valve installed after ED gradually until ultrasonic flow meter reading equal $5 \mathrm{~L} / \mathrm{min}$ at first parameter and equal 10L/min at second parameter to compare average salt rejection percentage between different three voltage values. Salt rejection percentages were estimated by EC-meter readings were recorded for $60 \mathrm{~min}$ (each 5min).

\subsubsection{Studied Power Types on Water Treatment Unit}

The power Types was studied at two parts (EMP and EP). The experiments were done at flow rate $51 / \mathrm{min}$ and voltage $12 \mathrm{v}$. Salt rejection percentages were estimated by EC-meter and readings were recorded for $60 \mathrm{~min}$ (each $5 \mathrm{~min}$ ).

\subsubsection{Using EMD before ED}

The input voltage was set to (12 volts) for each parts (EMP and EP), and voltage input was set to three different parameters $(12 \mathrm{v}, 24 \mathrm{v}$ and 36v). On the other hand, the experiments flow rate was fixed at $(51 / \mathrm{min})$. After that, the EC-meter readings were recorded for $60 \mathrm{~min}$ (each $5 \mathrm{~min}$ ).

\subsubsection{Using EMP before EP with Nano- coating}

EMP installed before EP which Electrodes were Covered with $\mathrm{H}_{2} \mathrm{Ti}_{3} \mathrm{O}_{7}$ Nano-coating to study coating effect. EP nano-coated plates had been installed into two parameters (4 plates coated -2 coated and 2 uncoated), and these two parameter were compared with control parameter (4 EP plates uncoated without EMP). For each parameter in this study, both 


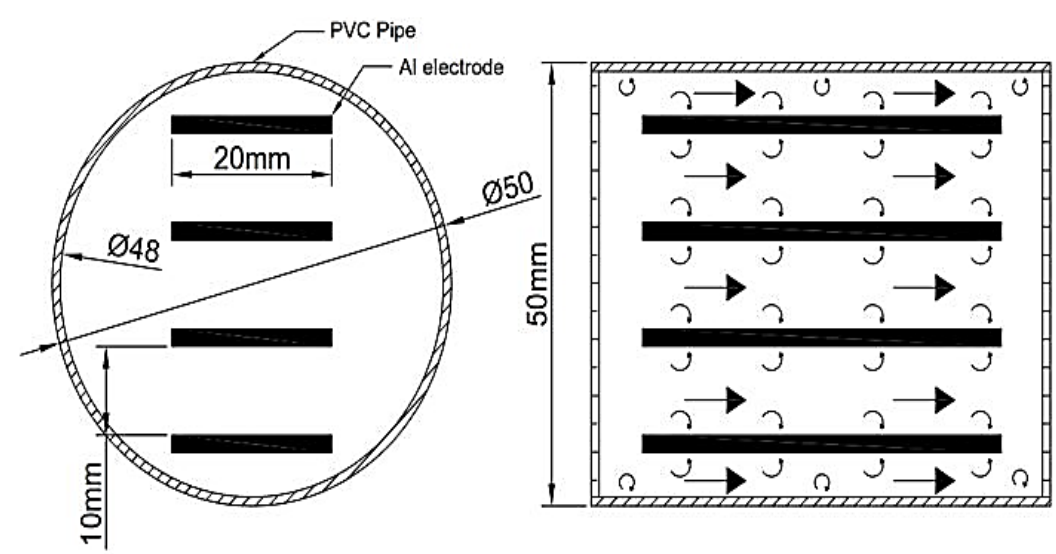

Fig 4. Water flow paths between electrodes into EP.

EP and EMP were connected with $12 \mathrm{v}$ DC input, and the experimental flow rate was fixed at $51 / \mathrm{min}$.

\subsection{Measurements}

The following measurements were determined at $25^{\circ} \mathrm{C}$ ambient temperature.

\subsubsection{Reynold's Number measurements}

Ultrasonic Flow Meter (SUP-2000H) was used to measure the flow velocity and Reynold's Number. Water type, pipe diameter, pipe material and pipe thickness were entered into the pass as an input data. Flow meter two sensors were fixed into three system components (PVC pipe-EMP -EP), and data recorded and had been shown in (Table 1).

\subsubsection{Voltage measurement}

Digital Multimeter (UT89X) was used to measure the voltage output from variable voltage power supply.

\subsubsection{Salinity measurement}

EC-meter (CX-401) was used to measure the water salinity in all experimental samples.

\subsection{Judgement indices}

\subsubsection{Salinity removal percentage}

In this study, water treatment unit consisted of two different parts (EMP and EP). These parts were evaluated by recording EC-meter (CX-401) values at different experimental conditions. Salt concentrations readings recorded for $60 \mathrm{~min}$ (each $5 \mathrm{~min}$ ).

\subsection{Statistical analysis}

Statistical analysis was performed using the SPSS software to determine and evaluate the Electrolysis Pass (EP) whether there are significant differences between the average readings of salt concentrations at different parameters voltage values. On the other hand, integrating Electromagnetic Pass (EMP) and Electrolysis Pass (EP) into one water treatment unit had been tested at three different voltage values. Finally, LSD test had been used to determine difference between three parameters to evaluate nano-coating Efficiency. 
Nano-coated Electrodes

Table 1. Characterization flow types within system at flow rate 51/min.

\begin{tabular}{|c|c|c|c|c|}
\hline \multirow{2}{*}{$\begin{array}{c}\text { System } \\
\text { component }\end{array}$} & \multicolumn{4}{|c|}{ Flow measurements } \\
\hline & $\begin{array}{l}\text { Velocity } \\
\mathrm{m} / \mathrm{s}\end{array}$ & $\begin{array}{c}\text { Exposure } \\
\text { Time } \\
\text { sec } \\
\end{array}$ & $\begin{array}{c}\text { Reynold's } \\
\text { No. }\end{array}$ & $\begin{array}{l}\text { Flow } \\
\text { Type }\end{array}$ \\
\hline $\begin{array}{c}\text { PVC Pipe } \\
\text { (Diameter } 28.4 \mathrm{~mm})\end{array}$ & 0.13 & 11.54 & 4000 & Turbulent \\
\hline $\begin{array}{c}\text { EMD } \\
\text { (Diameter 25mm) }\end{array}$ & 0.17 & 2.94 & 4700 & Turbulent \\
\hline $\begin{array}{c}\text { ED } \\
(\text { Diameter } 10 \mathrm{~mm})\end{array}$ & 0.13 & 2.7 & 1450 & Laminar \\
\hline
\end{tabular}

\section{Results and Discussions}

\subsection{Effect of Voltage on Salinity Removal Percentage}

At EP: salinity concentration readings recorded by EC-meter under flow rate $51 / \mathrm{min}$, these readings had been showed in Fig 5, The trend lines show that at the first five minutes there was a rapid change in the values of salinity readings at parameters $12 \mathrm{v}, 24 \mathrm{v}$ and $36 \mathrm{v}$. Time between minutes (6 to 10) gave a slow changes in trend lines, but time between minutes (11 to 60) gave a stable trend line close to the average readings of the values when the water passed through the ED. At ED voltage input $12 \mathrm{v}$, the mean of salt concentration readings was (1483 PPM) with percentage rejection $(1.13 \%)$. On the other hand, the mean of salt concentration readings at $24 \mathrm{v}$ was (1477 PPM) with percentage rejection (1.53\%). Finally, the results of readings at $36 \mathrm{v}$ show that saline water was reduced salt concentration on average (27 PPM) with percentage rejection $(1.8 \%)$. Increasing the voltage difference between the positive and negative electrodes leads to an increase in the forces of attraction between the ions and the electrodes, and this increase affects the amount of salt ions removed from the water.

\subsection{Effect of Power Types on Salinity Removal Percentage}

Salinity concentration readings showed in Fig 6, The trend lines show that at the first five minutes there was a rapid change in the values of salinity readings at treatment unit part EP, but the change in the values of salinity readings at treatment unit part EMP was very low. Time between minutes ( 6 to 60 ) gave a stable trend line close to the average readings of the values when the water passed through two parts (EMP and EP). At power type, EMP, the mean of salt concentration readings was (1495 PPM) with percentage rejection $(0.33 \%)$. On the other hand, the mean of salt concentration readings at EP was 1483 PPM with percentage rejection $(1.13 \%)$. Salt rejection percentage approved that electrolysis technology was better than electromagnetic field technology on salinity Removal Percentage.

3.3 Effect of Using Electromagnetic Pass (EMP) before Electrolysis Pass (EP) on Salinity Removal Percentage

\subsubsection{At EP voltage input $12 \mathrm{v}$}

Fig 7 shows that EMP which was installed before EP achieved positive results when EMP and EP were connected with power supply $12 \mathrm{v}$ output. Five treated water samples were taken 


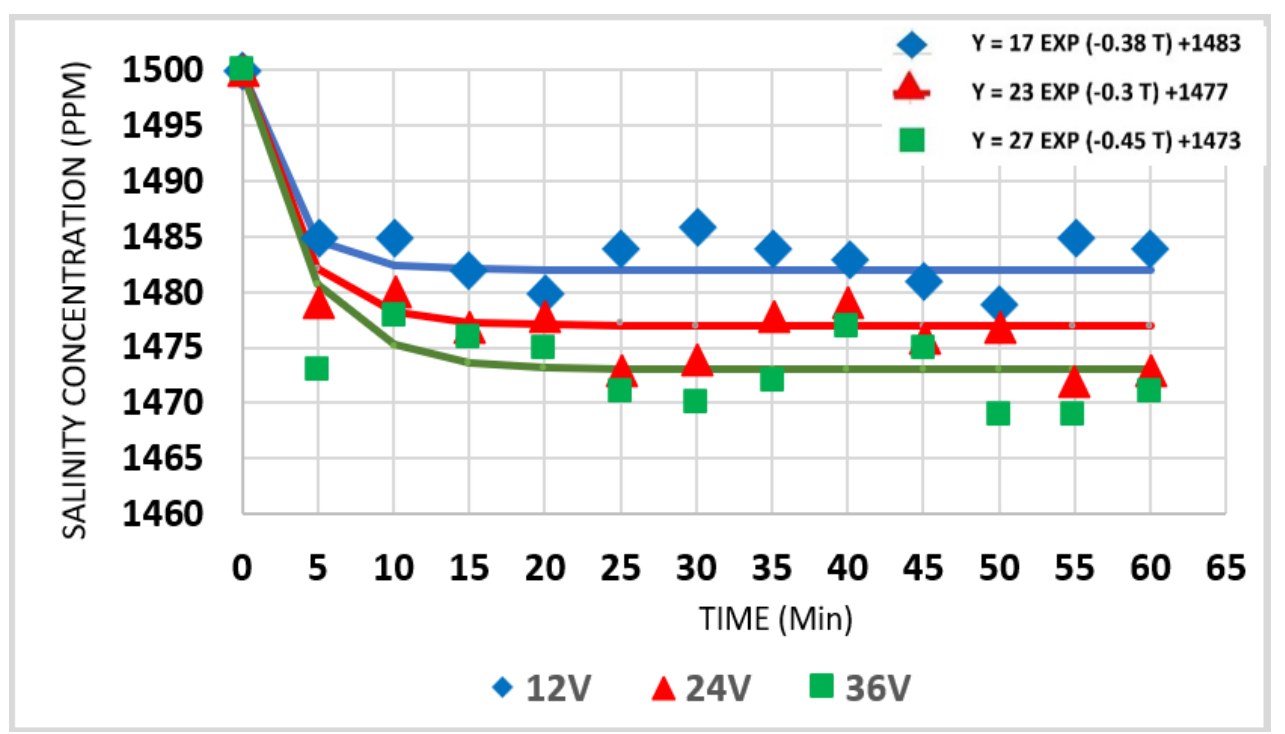

Fig 5. Comparison between 12, 24 and 36v DC power input on water electrolysis system at flow rate $5 \mathrm{~L} / \mathrm{min}$.

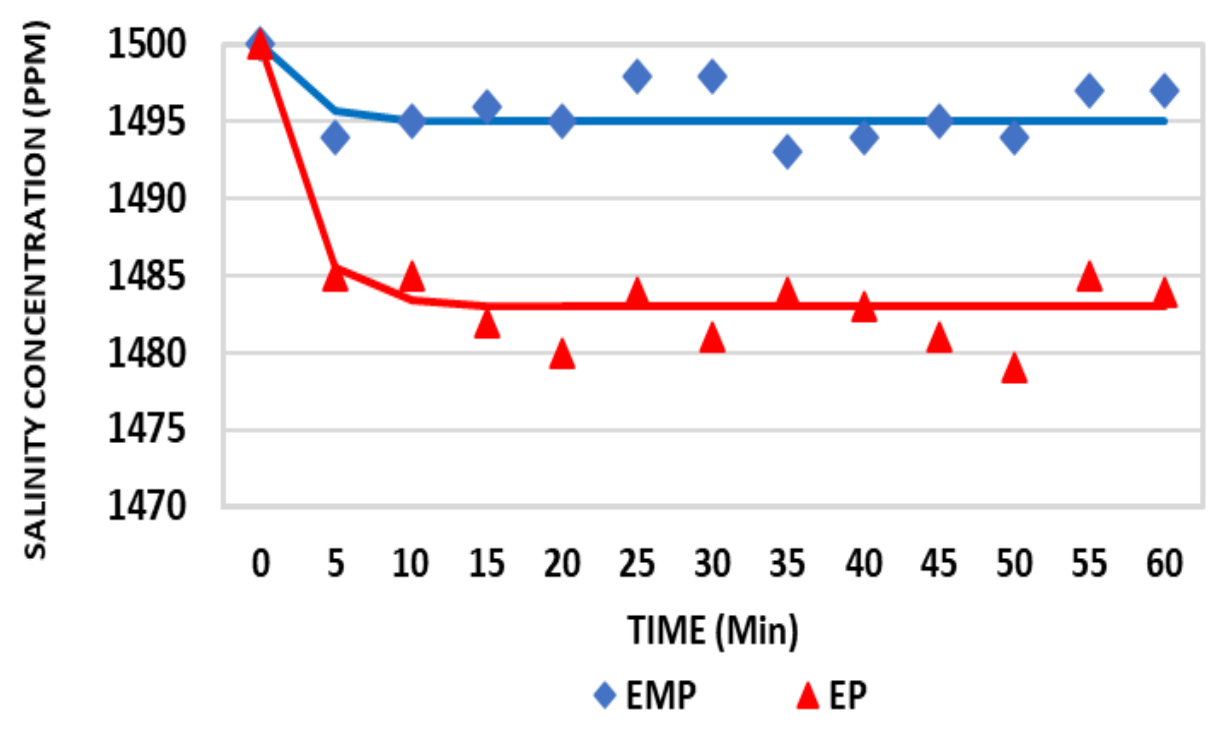

Fig 6. Comparison between two Power Types effect on Salinity Removal. 


\section{Nano-coated Electrodes}

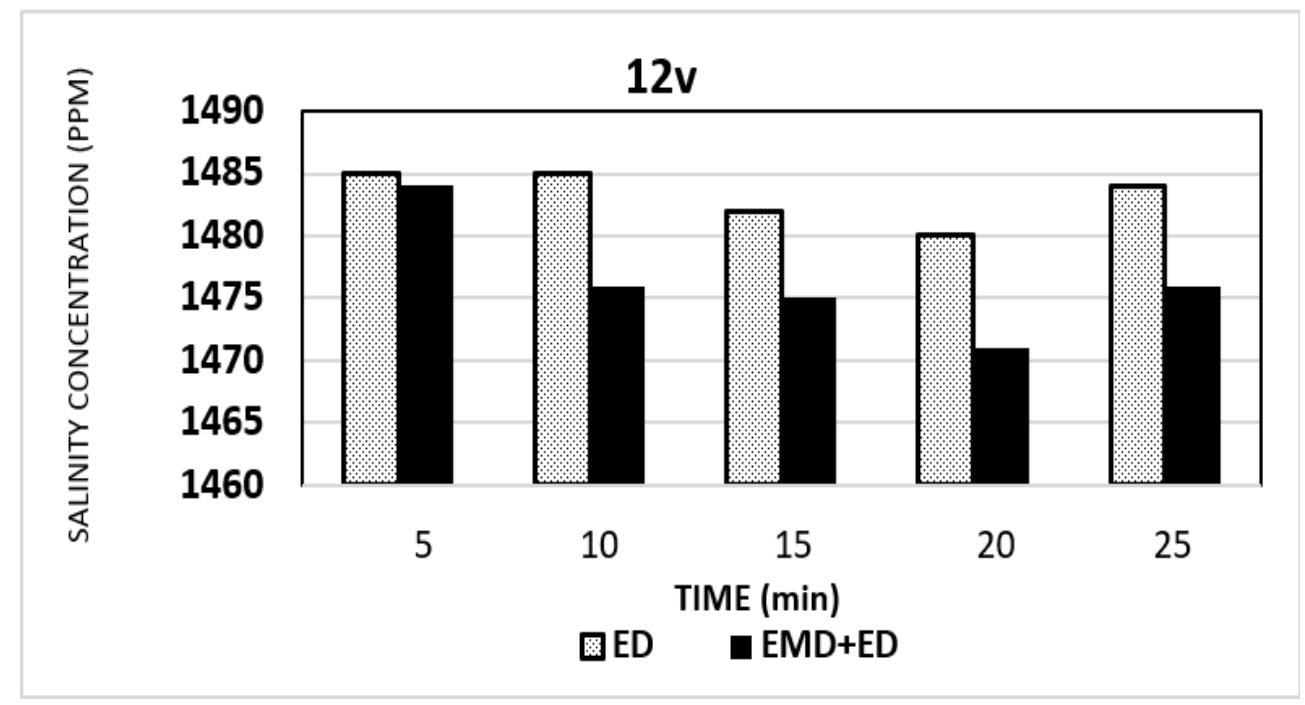

Fig 7. Comparison between (EP) and (EMP+EP) at EP voltage input $12 \mathrm{v}$.

after water treatment unit and measured by EC-meter each $5 \mathrm{~min}$. On the other hand, anther treatment unit consists of EP only connected with power supply $12 \mathrm{v}$ output, water passed through EP and five samples were taken and measured by EC-meter each $5 \mathrm{~min}$. Results when it compared showed that mean of salt concentration readings was (1476 PPM) with percentage rejection $(1.57 \%)$ at $(\mathrm{EMP}+\mathrm{EP})$ and mean of salt concentration readings was (1483 PPM) with percentage rejection (1.13\%) at (EP).

\subsubsection{At EP voltage input $24 v$}

Fig 8 shows that EMP which was installed before EP achieved positive results when EMP was connected with power supply $12 \mathrm{v}$ output, and EP was connected with power supply $24 \mathrm{v}$ output. Five treated water samples were taken after water treatment unit and measured by EC-meter each 5min. On the other hand, anther treatment unit consists of EP only connected with power supply $24 \mathrm{v}$ output, water passed through EP and five samples were taken and measured by EC-meter each $5 \mathrm{~min}$. Results when it compared showed that mean of salt concentration readings was (1473 PPM) with percentage rejection $(1.81 \%)$ at $(\mathrm{EMP}+\mathrm{EP})$ and mean of salt concentration readings was (1477 PPM) with percentage rejection (1.57\%) at (EP).

\subsubsection{At EP voltage input 36v}

Fig 9 shows that EMP which was installed before EP achieved positive results when EMP was connected with power supply $12 \mathrm{v}$ output, and EP was connected with power supply 36v output. Five treated water samples were taken after water treatment unit and measured by EC-meter each $5 \mathrm{~min}$. On the other hand, anther treatment unit consists of EP only connected with power supply $36 \mathrm{v}$ output, water passed through EP and five samples were taken and measured by EC-meter each $5 \mathrm{~min}$. Results when it compared showed that mean of salt concentration readings was (1472 PPM) with percentage rejection $(1.85 \%)$ at $(\mathrm{EMP}+\mathrm{EP})$ and mean of salt concentration readings was (1473 PPM) with percentage rejection (1.8\%) at (EP). 


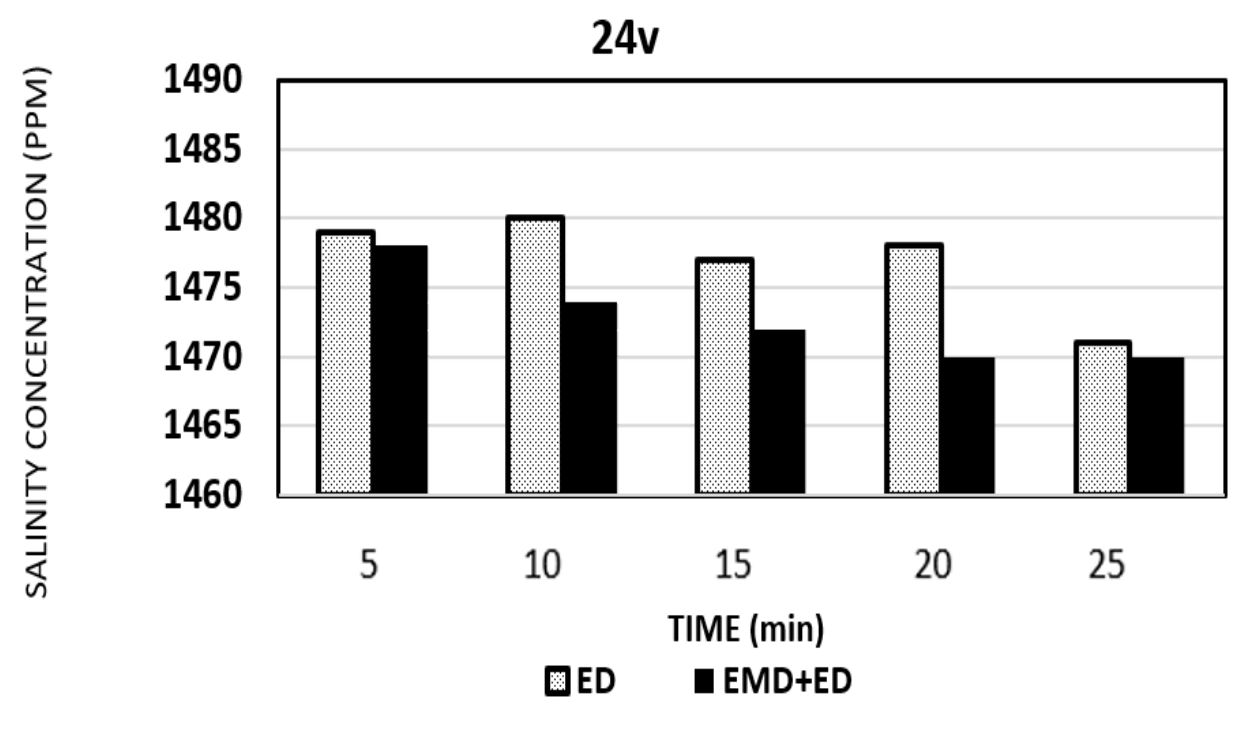

Fig 8. Comparison between (EP) and (EMP+EP) at EP voltage input 24v.

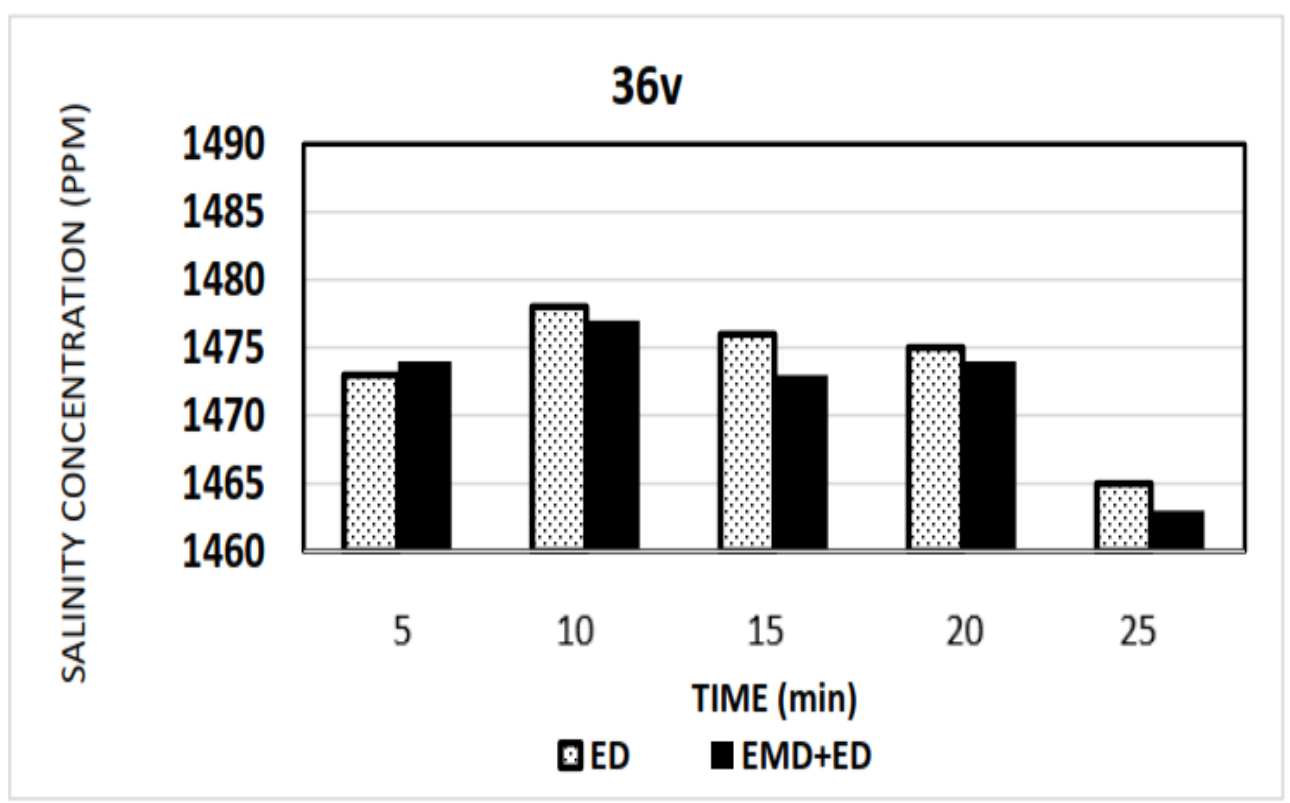

Fig 9. Comparison between (EP) and (EMP+EP) at EP voltage input 36v. 


\subsection{Effect of Using EMP before EP which Electrodes were Covered with $\mathrm{H}_{2} \mathrm{Ti}_{3} \mathrm{O}_{7}$ Nano-coating on Salinity Removal Percent- age}

Salinity concentration readings recorded by EC-meter under flow rate $5 \mathrm{~L} / \mathrm{min}$ and voltage value $12 \mathrm{v}$, these readings had been taken from three different parameters (((EMP+EP (4 plates uncoated as a control parameter)) (EMD+EP (2 coated and 2 uncoated)) $(\mathrm{EMP}+\mathrm{EP}$ (4 plates coated $))$ ) and it was showed in Fig 10, The trend lines show that at the first five minutes there was a rapid change in the values of salinity readings at parameters all parameters. Time between minutes ( 6 to 10 ) gave a slow changes in trend lines, but time between minutes (11 to 60) gave a stable trend line close to the average readings of the values when the water passed through the EP. At ((EMP+EP (4 plates uncoated)), the mean of salt concentration readings was (1476 PPM) with percentage rejection $(1.6 \%)$. On the other hand, the mean of salt concentration readings at (EMP+EP (2 coated and 2 uncoated)) was (1464 PPM) with percentage rejection (2.4\%). Finally, the results of readings at $(\mathrm{EMP}+\mathrm{EP}$ (4 plates coated)) showed that saline water was reduced salt concentration on average (51 PPM) with percentage rejection (3.4\%). Increasing the electrodes nano-coated surface area leads to an increase at the amount of salt ions removed from the treated water.

Fig 11 presented the most important results that were obtained by using the unit parts which designed during this study. The water treatment unit consisting of EP only achieved the lowest percentage of salt rejecting from the treated water. While, when EMP was combined with EP, this led to an increase in the percentage of salt rejecting to $1.6 \%$ under the same conditions. The addition of nano-coating contributed to an increase in the percentage of rejecting salts and achieved $2.4 \%$ at (EMP+EP ( 2 coated and 2 uncoated)), and by increasing the area of the nano-coated surface, the percentage of rejecting salts increased to $3.4 \%$.

\subsection{Statistical analysis}

\subsubsection{Electrolysis Pass (EP) Evaluation}

The EP was evaluated at $5 \mathrm{~L} / \mathrm{min}$ to determine the most appropriate voltage input between 12v, 24v and 36v. Based on (Table 2), the voltage input $24 \mathrm{v}$ and $36 \mathrm{v}$ were achieved a significant difference with $12 \mathrm{v}$ but the difference between $24 \mathrm{v}$ and $36 \mathrm{v}$ were not significant.

\subsubsection{Power Types Evaluation}

EP was compared with EMP at $12 \mathrm{v}$ voltage input to determine the most appropriate power type. The significance of the differences between their averages were achieved according to (Table 3) a significant difference between the two averages at the 0.05 confidence level. This test highlighted that electrolysis technology was better than electromagnetic field technology on salinity Removal Percentage.

EMP with EP were evaluated at $51 / \mathrm{min}$ to determine EMP effect when they integrated into same water treatment unit, and significance was tested by three statistical analyzes at 12,24 and 36 volts. Results showed that electromagnetic field was achieved a significant difference with EP at $12 \mathrm{v}$ parameter, While a non-significant difference with EP at $24 \mathrm{v}$ parameter. Finally, electromagnetic field was achieved a non-significant difference with $\mathrm{EP}$ at 36v parameter, as shown in (Table 4).

\subsubsection{Nano-coating Evaluation}

Titanat nano-coating evaluated at flow rate $5 \mathrm{~L} / \mathrm{min}$ and voltage $12 \mathrm{v}$ to determine coating effect. According to (Table 5), a control parameter (EMP+EP (4 plates uncoated)) was achieved a significant difference with all coating parameters, and the results demonstrated that increasing the surface area of the electrode coated with nano-coating increases the efficiency of removing salts from the water. 


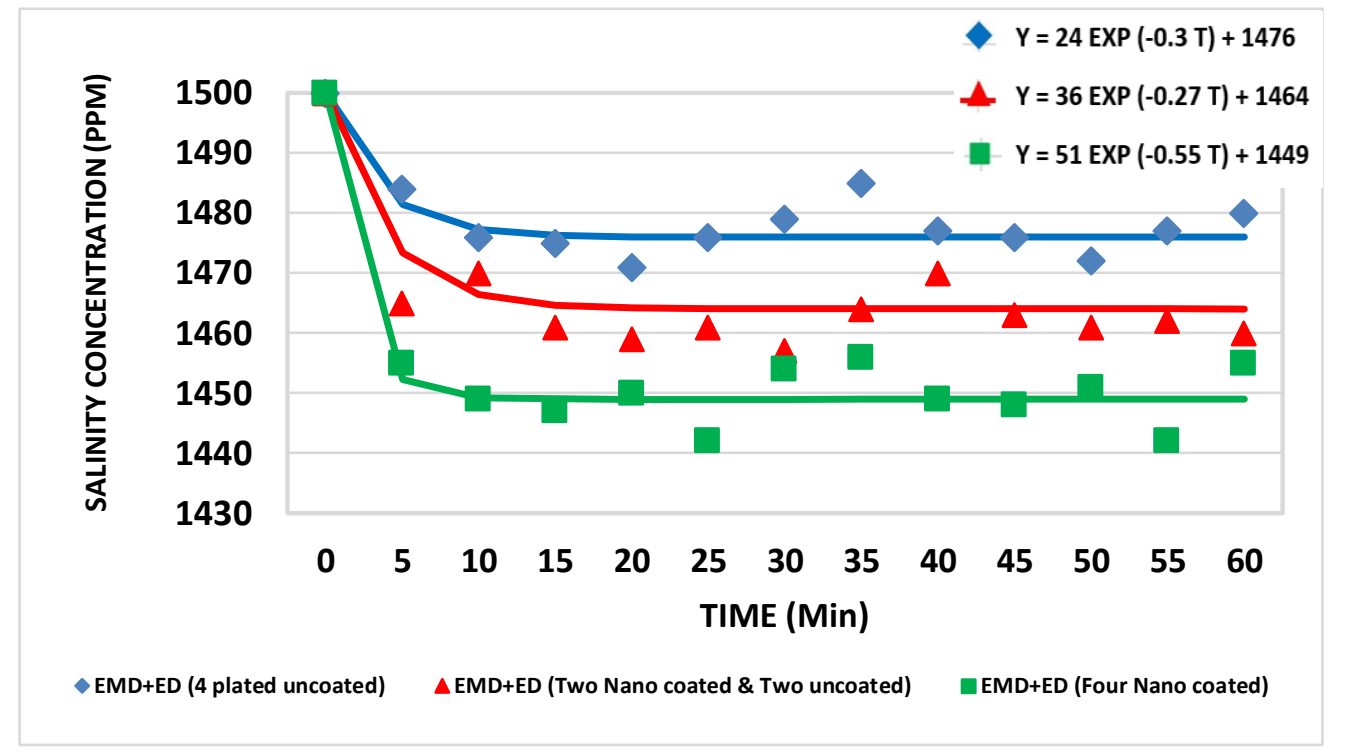

Fig 10. Comparison between ( 4 plates coated -2 coated and 2 uncoated -4 plates uncoated).

圆ED EMD+ED $\triangle \mathrm{EMD}+\mathrm{ED}$ (2 coated -2 uncoated) $\square \mathrm{EMD}+\mathrm{ED}$ (4 plates coated)

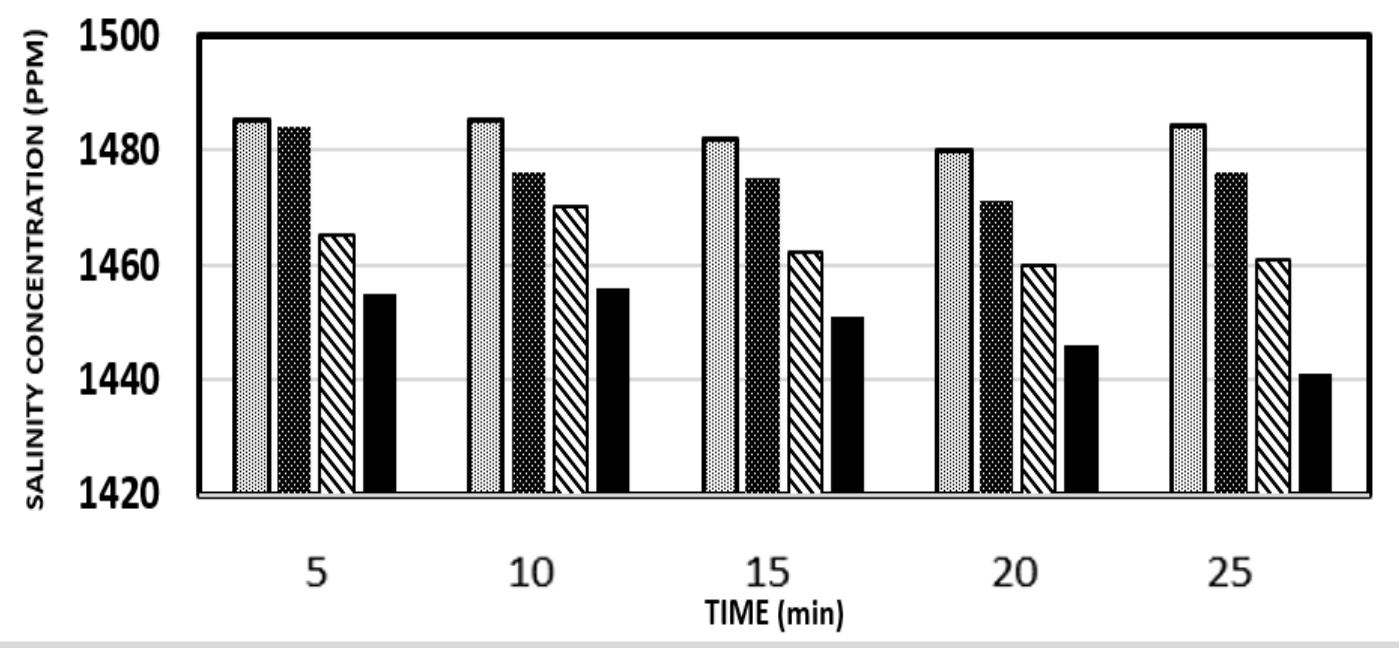

Fig 11. Comparison between all parameters on this study. 
Nano-coated Electrodes

Table 2. Difference between voltage parameters at flow rate $51 / \mathrm{min}$ according to LSD test.

Dependent Variable: Concentrations

LSD

\begin{tabular}{|c|c|c|c|c|c|c|}
\hline \multirow[b]{2}{*}{ (l) Voltage } & \multirow[b]{2}{*}{ (j) Voltage } & \multirow{2}{*}{$\begin{array}{c}\text { Mean } \\
\text { Difference } \\
(\mathbf{l}-\mathbf{j})\end{array}$} & \multirow[b]{2}{*}{ Std Error } & \multirow[b]{2}{*}{ Sig. } & \multicolumn{2}{|c|}{ 95\% Confidence Interval } \\
\hline & & & & & $\begin{array}{l}\text { Lower } \\
\text { Bound }\end{array}$ & $\begin{array}{l}\text { Upper } \\
\text { Bound }\end{array}$ \\
\hline $12 \mathrm{v}$ & $24 v$ & $6.75^{*}$ & 1.098 & 0.000 & 4.52 & 8.98 \\
\hline & $36 v$ & $8.417^{*}$ & 1.098 & 0.000 & 6.18 & 10.65 \\
\hline $24 v$ & $12 \mathrm{v}$ & $-6.75^{*}$ & 1.098 & 0.000 & -8.98 & -4.52 \\
\hline & $36 v$ & 1.667 & 1.098 & 0.139 & -0.57 & 3.90 \\
\hline $36 v$ & $12 \mathrm{v}$ & $-8.417^{*}$ & 1.098 & 0.000 & -10.65 & -6.18 \\
\hline & $24 v$ & -1.667 & 1.098 & 0.139 & -3.90 & 0.57 \\
\hline
\end{tabular}

*. The mean difference is significant at the 0.05 level.

Table 3. Difference between two power types (EMP and EP)

\begin{tabular}{|c|c|c|c|c|c|c|}
\hline \multicolumn{2}{|c|}{} & $\begin{array}{c}\text { Levene's Test } \\
\text { Equality of } \\
\text { variances }\end{array}$ & \multicolumn{4}{|l|}{} \\
\cline { 3 - 8 } & Equal variance assumed & 1.115 & 0.302 & 16.455 & 22 & 0.000 \\
\hline Concentrations & Sig. & t & df & $\begin{array}{c}\text { Sig. } \\
(2-t a i l e d)\end{array}$ \\
\hline & Equal variance not assumed & & & 16.455 & 21.005 & 0.000 \\
\hline
\end{tabular}

Table 4. difference between (EMD+ED) and ED at $(12 \mathrm{v}-24 \mathrm{v}-36 \mathrm{v})$

\begin{tabular}{|c|c|c|c|c|c|c|}
\hline \multicolumn{2}{|c|}{} & \multicolumn{2}{|c|}{$\begin{array}{c}\text { Levene's Test } \\
\text { Equality of } \\
\text { variances }\end{array}$} & \multicolumn{4}{|l|}{} \\
\cline { 3 - 8 } & 12v & F & Sig. & t & df & $\begin{array}{c}\text { Sig. } \\
(2-t a i l e d)\end{array}$ \\
\hline Concentrations & Equal variance assumed & 0.738 & 0.4 & 5.160 & 22 & 0.000 \\
\hline & Equal variance not assumed & & & 5.160 & 18.166 & 0.000 \\
\hline
\end{tabular}

\begin{tabular}{|c|c|c|c|c|c|c|}
\hline \multicolumn{2}{|c|}{} & \multicolumn{2}{|l|}{$\begin{array}{c}\text { Levene's Test } \\
\text { Equality of } \\
\text { variances }\end{array}$} & \multicolumn{4}{|l|}{} \\
\cline { 3 - 8 } & $\mathbf{2 4 v}$ & F & Sig. & t & df & $\begin{array}{c}\text { Sig. } \\
(2-t a i l e d)\end{array}$ \\
\hline Concentrations & Equal variance assumed & 0.257 & 0.617 & 1.657 & 22 & 0.112 \\
\hline & Equal variance not assumed & & & 1.657 & 19.881 & 0.113 \\
\hline
\end{tabular}

\begin{tabular}{|c|c|c|c|c|c|c|}
\hline \multicolumn{2}{|c|}{} & \multicolumn{2}{|c|}{$\begin{array}{c}\text { Levene's Test } \\
\text { Equality of } \\
\text { variances }\end{array}$} & \multicolumn{4}{|c|}{} \\
\cline { 3 - 8 } & F & Sig. & t & df & $\begin{array}{c}\text { Sig. } \\
(2-t a i l e d)\end{array}$ \\
\hline Concentrations & Equal variance assumed & 0.625 & 0.438 & 1.326 & 22 & 0.198 \\
\hline & Equal variance not assumed & & & 1.326 & 19.61 & 0.2 \\
\hline
\end{tabular}


Table 5. significant difference between all titanat nano-coated electrodes parameters Dependent Variable: Concentrations

LSD

\begin{tabular}{|c|c|c|c|c|c|c|}
\hline \multirow[t]{2}{*}{ (l) Coating } & \multirow[t]{2}{*}{ (j) Coating } & \multirow{2}{*}{$\begin{array}{c}\text { Mean } \\
\text { Difference } \\
(\mathbf{l}-\mathbf{j})\end{array}$} & \multirow[b]{2}{*}{ Std Error } & \multirow[b]{2}{*}{ Sig. } & \multicolumn{2}{|c|}{$\begin{array}{l}\text { 95\% Confidence } \\
\text { Interval }\end{array}$} \\
\hline & & & & & $\begin{array}{l}\text { Lower } \\
\text { Bound }\end{array}$ & $\begin{array}{l}\text { Upper } \\
\text { Bound }\end{array}$ \\
\hline \multirow[t]{2}{*}{$\begin{array}{l}\text { EMD+ED (4 plates } \\
\text { uncoated) }\end{array}$} & $\begin{array}{c}\text { EMD+ED ( } 2 \text { plates } \\
\text { coated and } 2 \\
\text { uncoated })\end{array}$ & $14.583^{*}$ & 1.762 & 0.00 & 11 & 18.17 \\
\hline & $\begin{array}{c}\text { EMD+ED (4 plates } \\
\text { coated })\end{array}$ & $27.5^{*}$ & 1.762 & 0.00 & 23.92 & 31.08 \\
\hline \multirow[t]{2}{*}{$\begin{array}{c}\text { EMD+ED (2 plates } \\
\text { coated and } 2 \text { uncoated })\end{array}$} & $\begin{array}{c}\text { EMD+ED (4 plates } \\
\text { uncoated) }\end{array}$ & $-14.583 *$ & 1.762 & 0.00 & -18.17 & -11 \\
\hline & $\begin{array}{c}\text { EMD+ED (4 plates } \\
\text { coated) }\end{array}$ & $12.917 *$ & 1.762 & 0.00 & 9.33 & 16.5 \\
\hline \multirow[t]{2}{*}{$\begin{array}{l}\text { EMD+ED (4 plates } \\
\text { coated) }\end{array}$} & $\begin{array}{c}\text { EMD+ED (4 plates } \\
\text { uncoated) }\end{array}$ & $-27.5^{*}$ & 1.762 & 0.00 & -31.08 & -23.92 \\
\hline & $\begin{array}{c}\text { EMD+ED ( } 2 \text { plates } \\
\text { coated and } 2 \\
\text { uncoated }) \\
\end{array}$ & $-12.917 *$ & 1.762 & 0.00 & -16.5 & -9.33 \\
\hline
\end{tabular}

*. The mean difference is significant at the 0.05 level.

\section{Conclusions}

In this study, marginal-quality water treatment unit has been designed, and consisted of two parts (Electromagnetic Pass and Electrolysis Pass). This study can be concluded that laminar flow $(5 \mathrm{~L} / \mathrm{min})$ inside EP was better than turbulent flow $(10 \mathrm{~L} / \mathrm{min})$ in the electrolysis experiment and the mean of salt concentration readings was 1473 and $1494 \mathrm{PPM}$, respectively. The voltage input $24 \mathrm{v}$ and $5 \mathrm{~L} / \mathrm{min}$ flow rate were achieved the best parameter after EP evaluated. The EMP when it installed before EP achieved positive results at 12,24 , and $36 \mathrm{~V}$ parameters with salt rejection percentage rates $1.57 \%, 1.81 \%$ and $1.85 \%$, respectively. Titanate nano-coating when coated into Aluminum plates, was the most recorded positive result with a salinity removal percentage $3.4 \%$. On the other hand, different other parameters (2 coated and 2 uncoated -4 plates uncoated) recorded salinity removal percentage $2.4 \%$ and $1.13 \%$, respectively. This study is promising and opens the way for integrating both electrolysis and electromagnetic field technologies with on-farm irrigation systems and enhancing their efficiency using nanotechnology.

\section{References}

Abdel-Shafy HI, Kamel AH (2016) Groundwater in Egypt issue: Resources, location, amount, contamination, protection, renewal, future overview. Egyptian Journal of Chemistry, 59, 332-333.

Assar IMG, Mahmod W, Fujii M (2019) Assessing the agricultural drainage water with water quality indices in the El-Salam Canal Mega Project, Egypt. Journal of Water (Switzerland) 11, 1-5. 


\section{Nano-coated Electrodes}

Brouwer C, Heibloem M (1986) Irrigation water management: irrigation water needs. Training manual. The Food and Agriculture Organization (FAO), 1-103.

Fernando FP, Luis R, Antonio EK, Rafael L (2015) Response of lettuce crop to magnetically treated irrigation water and different irrigation depths. African Journal of Agricultural Research 10, 2300-2308.

Hachicha M, Kahlaoui B, Khamassi N, Jouzdan O (2018) Effect of electromagnetic treatment of saline water on soil and crops. Journal of the Saudi Society of Agricultural Sciences $17,4-8$.

Johnson G, Zhang H (2017) Classification of Irrigation Water Quality. Oklahoma State University--Division of Agricultural Sciences and Natural Resources--Cooperative Extension Service, 2-3.
Lai SW, Park JW, Yoo SH, Song EH (2016) Surface synergism of $\mathrm{Pd} / \mathrm{H} 2 \mathrm{Ti} 3 \mathrm{O} 7$ composite nanowires for catalytic and photocatalytic hydrogen production from ammonia borane. International Journal of Hydrogen Energy 41, 3428-3435.

Liu W, Zhao X, Wang T, Fu J (2015) Selective and irreversible adsorption of mercury (II) from aqueous solution by a flower-like titanate nanomaterial. Journal of Materials Chemistry 34,

Malakar A, Snow DD, Ray C (2019) Irrigation water quality-A contemporary perspective. Journal of Water (Switzerland) 11,

Sharbat A (2016) Electrodialysis Desalination System. Desalination and Water Purification Research and Development Program 15, 1-15.

Zaki AH, Naeim AA, EL-Dek SI (2019) Sodium titanate nanotubes for efficient transesterification of oils into biodiesel. Environmental Science and Pollution Research 26, 36389-36390. 